Images in...

\title{
Thoracic aortic aneurysm causing platypnoea and dorsalgia
}

\author{
Pedro Lourenço Gomes, Sérgio Barra, Rui Providência, António Leitão-Marques \\ Cardiology Department, Coimbra's Hospital Centre and University, Coimbra, S Martinho do Bispo, Portugal \\ Correspondence to Dr Rui Providência, rui_providencia@yahoo.com
}

\section{DESCRIPTION}

A 70-year-old male patient with no previous history of cardiovascular complaints was referred to the emergency department due to progressively aggravating dyspnoea and diminishing functional capacity (starting 12 months before) and abnormal findings in a chest $\mathrm{x}$-ray suggesting possible expansion of the thoracic aorta (figure 1). One month before admission, the patient started complaining about dizziness and dyspnoea induced by the upright position and relieved by recumbency - platypnoea. He denied orthopnoea, paroxysmal nocturnal dyspnoea or angina. He had retired 10 years before due to dorsalgia thought to be of musculoskeletal origin. A thoracic CT scan (figure 2) was performed and revealed a $10 \mathrm{~cm}$ sized thoracic aortic aneurysm (luminal size: $4.5 \mathrm{~cm}$ ), starting below the exit of the left subclavian artery and reaching the inferior third of the thoracic aorta. It eroded four thoracic vertebrae (T5-T8) and caused significant collapse of the left atrium. Transthoracic and transesophageal echocardiograms (figure 3) were performed, unveiling a partially collapsed left atrium (antero-posterior diameter of $11 \mathrm{~mm}$ in longaxis left paraesternal view). The patient underwent surgery, with placement of an endovascular stent graft. Two years following the intervention, the patient is practically asymptomatic. Compression of lumbar vertebrae is occasionally caused by abdominal aortic aneurysms. However, back pain resulting from erosion of thoracic vertebrae by an aortic aneurysm is an extremely rare finding. Furthermore, platypnoea caused by compression of the left atrium by an aneurysmatic aorta is very uncommon.

\section{Learning points}

- Thoracic aortic aneurysms may have extremely atypical presentations, such as platypnoea, presumably caused by left atrium compression in the upright position, and dorsalgia due to compression of thoracic vertebrae.

- An aortic aneurysm may grow to substantial dimensions before causing significant symptoms.

- Chronic lumbago or dorsalgia should not be automatically attributed to musculoskeletal causes.

- A chest or abdominal $\mathrm{x}$-ray should be considered in patients with persistent lumbago or dorsalgia, especially in the presence of cardiovascular risk factors.

\section{Competing interests None.}

Patient consent Obtained.

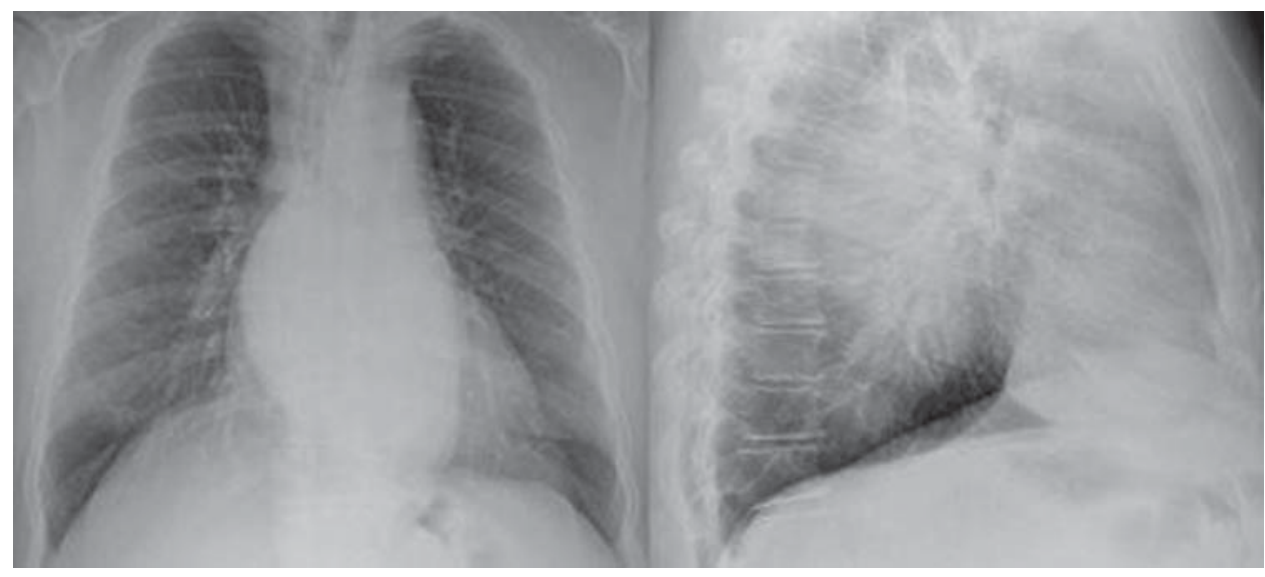

Figure 1 Chest $\mathrm{X}$-ray suggesting possible expansion of the thoracic Aorta and erosion of thoracic vertebrae 


\section{BMJ Case Reports}

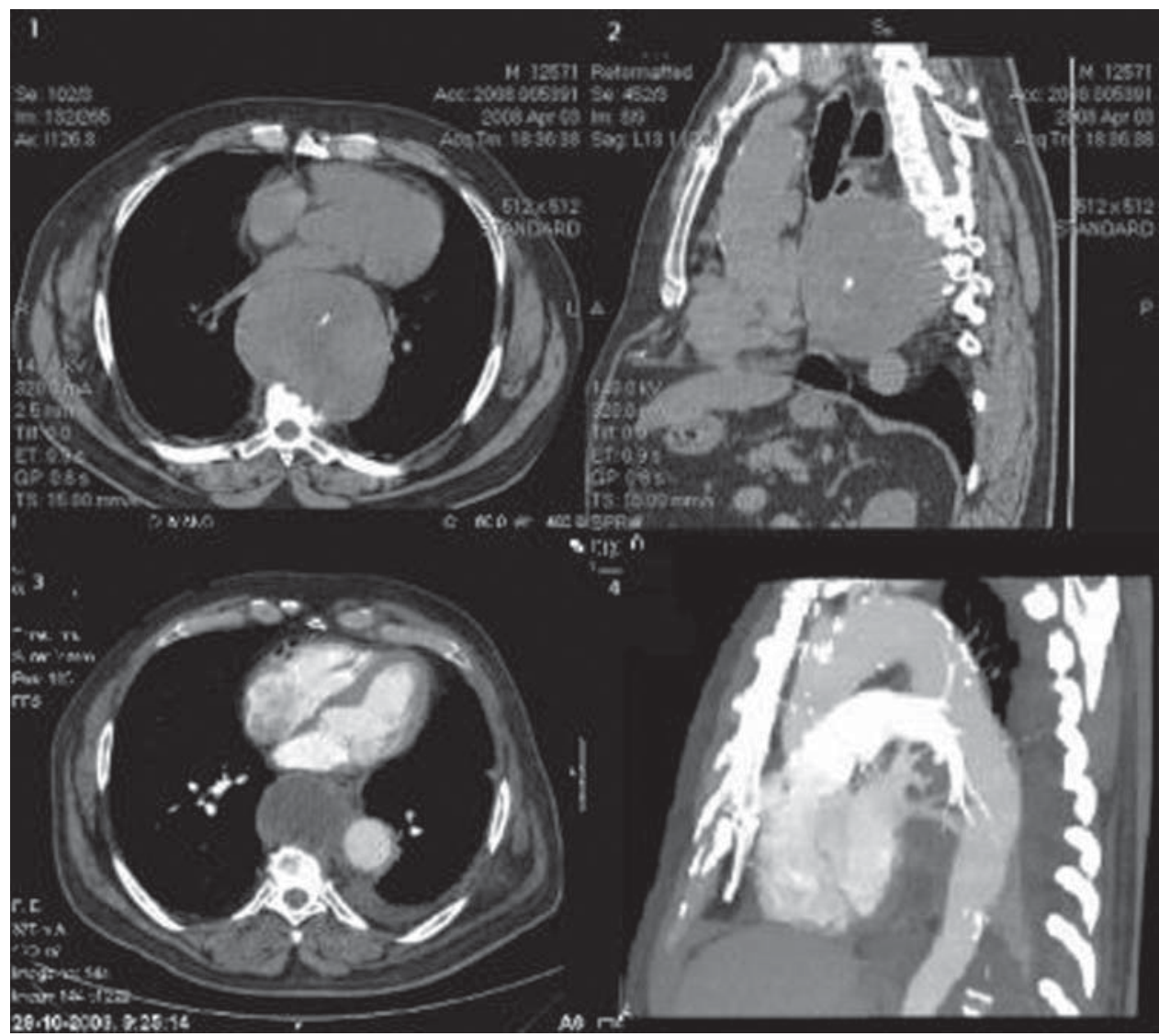

Figure 2 Chest CT showing a $10 \mathrm{~cm}$ sized thoracic aortic aneurysm starting below the exit of the left subclavian artery and reaching the inferior third of the thoracic aorta, eroding four thoracic vertebrae (T5-T8) and causing significant collapse of the left atrium. 


\section{BMJ Case Reports}

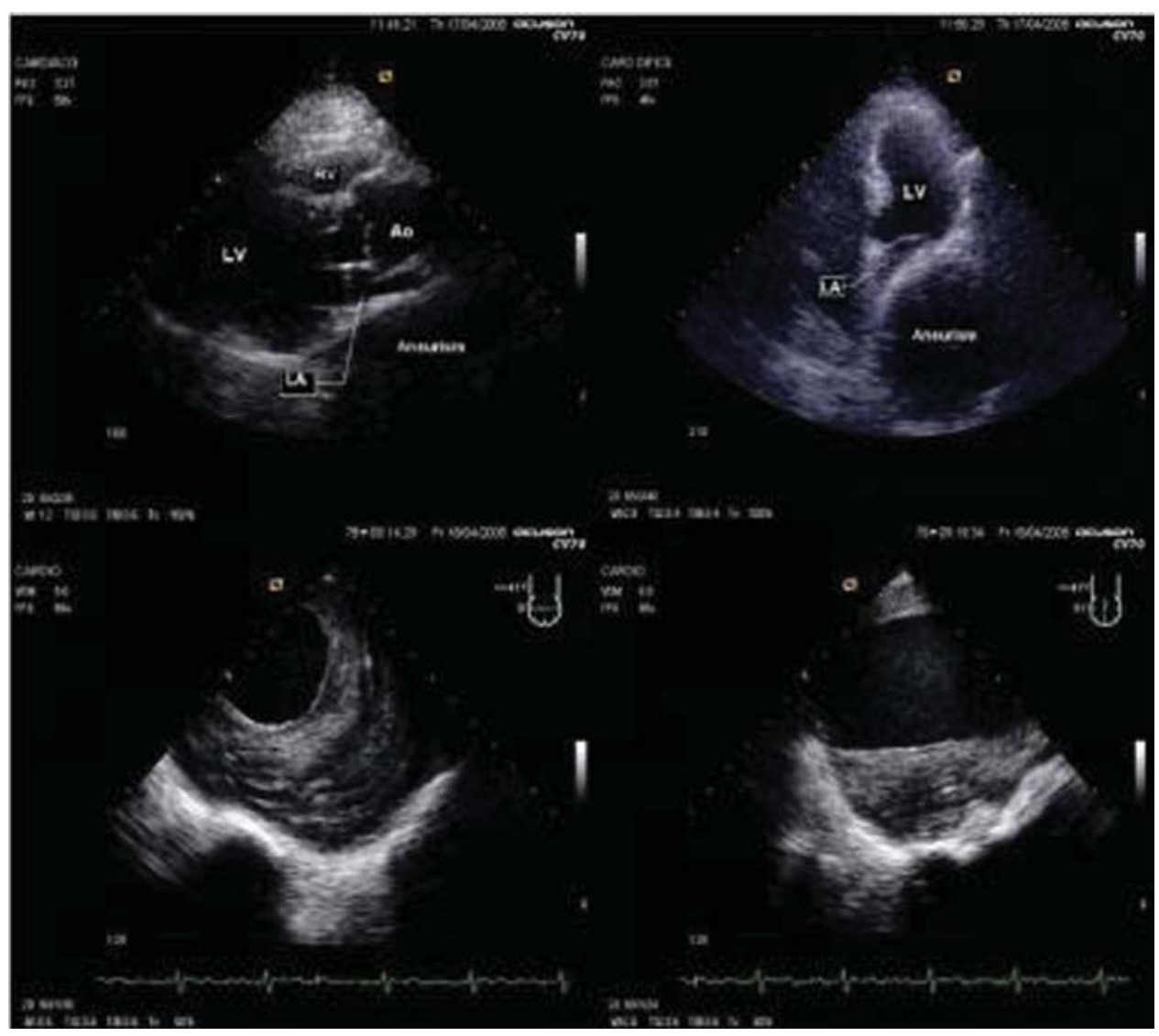

Figure 3 Transthoracic echocardiogram (upper panels) showing a partially collapsed left atrium. On transesophageal (lower panels) the wall of thoracic aortic aneurism can be observed.

This pdf has been created automatically from the final edited text and images.

Copyright 2012 BMJ Publishing Group. All rights reserved. For permission to reuse any of this content visit http://group.bmi.com/group/rights-licensing/permissions.

BMJ Case Report Fellows may re-use this article for personal use and teaching without any further permission.

Please cite this article as follows (you will need to access the article online to obtain the date of publication).

Gomes PL, Barra S, Providência R, Leitão-Marques A. Thoracic aortic aneurysm causing platypnoea and dorsalgia. BMJ Case Reports 2012;10.1136/bcr.02.2012.5879, Published XXX

Become a Fellow of BMJ Case Reports today and you can:

- Submit as many cases as you like

- Enjoy fast sympathetic peer review and rapid publication of accepted articles

- Access all the published articles

- Re-use any of the published material for personal use and teaching without further permission

For information on Institutional Fellowships contact consortiasales@bmjgroup.com

Visit casereports.bmj.com for more articles like this and to become a Fellow

Keep up to date with all published cases by signing up for an alert (all we need is your email address) http://casereports.bmj.com/cgi/alerts/etoc 